\title{
Assessing the resettlement reforms under Transforming Rehabilitation
}

Matt Cracknell presents key findings from his research on resettlement policy and practice in England and Wales.

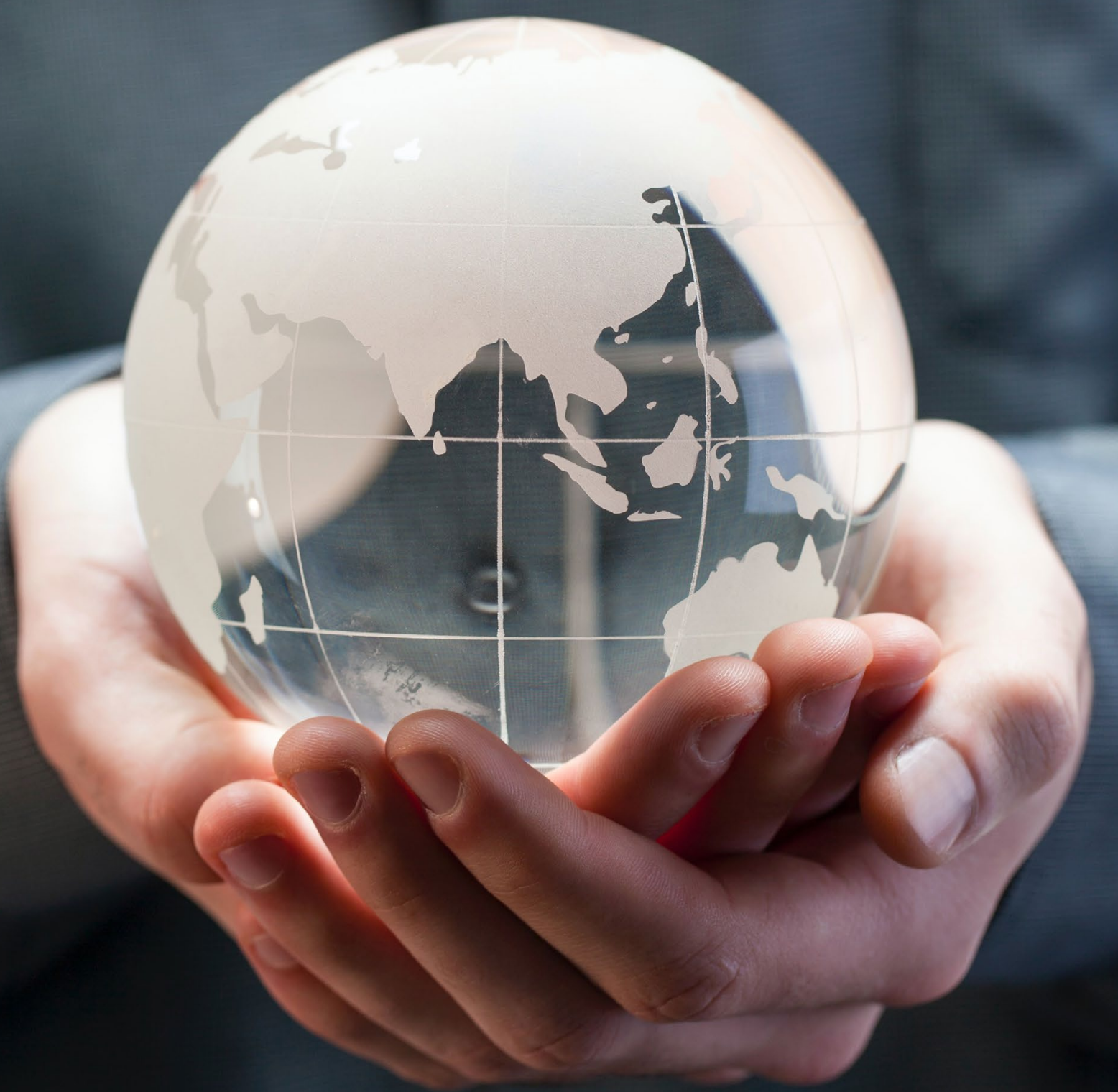




\section{Introduction}

Introduced as a part of the Transforming Rehabilitation (TR) reforms, the Offender Rehabilitation Act (ORA) 2014 extended postrelease supervision to the short sentence population, a cohort who have historically been neglected in penal discourse. The ORA 2014 reforms meant that everyone released from custody on a short sentence receives 12 -months post-release supervision in the community. In this article I present some of the findings from my PhD which I completed in July 2020. The main aim of the thesis was to explore how resettlement is enacted by practitioners and experienced by individuals serving short sentences. I interviewed 35 practitioners and service users in one local resettlement prison and one CRC office, in order to gain a rich qualitative perspective of how the ORA 2014 reforms were enacted on the ground.

This extension of post-release support has occurred in three ways. Firstly, 'local' Category B prisons were re-designated as 'resettlement' prisons. This policy was intended to result in individuals serving short sentences "working towards their rehabilitation" from the moment they were imprisoned and being provided with a "tailored package of supervision and support" in the form of through the gate resettlement services (Ministry of Justice, 2013). Secondly, support begun in prison would continue seamlessly through-the-gate and into the community. The needs of the individual would be identified in prison and then communicated to a dedicated CRC practitioner, who would put the resettlement plan into action. Once released into

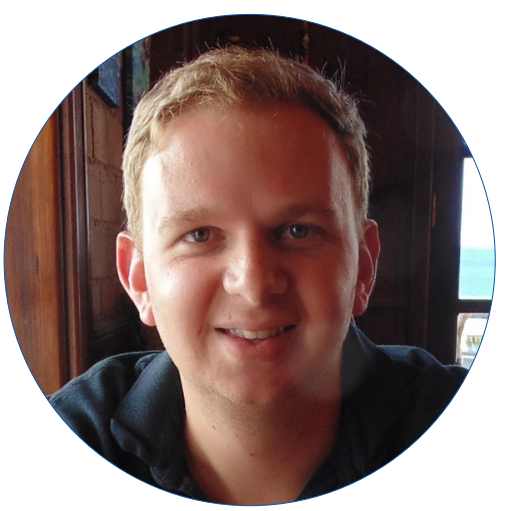

Matt Cracknell

Lecturer in Criminology, Middlesex University

the community under licence, the officer would undertake regular supervision sessions with the individual to provide support and guidance in the first crucial weeks post-release. The third element of this sentence is post-sentence supervision (PSS). With the expressed aim of rehabilitation, PSS is facilitated by a specialist worker from a third-sector organisation, who has access to a range of specialist providers. This final part of the sentence should allow the service user to consolidate their resettlement plans as they reintegrate back into the community. 


\section{The resettlement prison}

Institutional barriers in the resettlement prison primarily concerned the difficulties of overseeing the pre-existing demands of the 'local' functions of facilitating court transfers and managing remand prisoners, alongside the nascent ideals of providing resettlement support. Practitioners felt the prison was not sufficiently equipped to provide this additional support. This resulted in prisoners becoming trapped within a prison that was unable to meet their needs. Furthermore, prison officers failed to recognise resettlement work as a core part of their working remit. Instead, resettlement was largely understood as a technical process to be administered by a specific department, rather than through a whole prisons approach. This indicated a failure to alter the role of officers beyond core security concerns.

For practitioners with a resettlement focused role, temporal constraints hampered the ability to provide meaningful support. Although practitioners tried their best, the limited time to provide resettlement support inhibited their ability to facilitate meaningful change. Instead, resettlement planning was either not done, or completed to a superficial standard, and became viewed as a box-ticking exercise rather than a tool to engage meaningfully with an individual. Furthermore, austerity measures had affected prison staffing levels and created a pervasive culture of ambivalence and acceptance of underperformance within the prison. These political-economic barriers had also impacted upon the prisons' ability to provide effective pathway services. Combined, these issues undermined the ideals of the resettlement prison and the ability to support individuals as they transitioned through the gate.

\section{Through-the-gate transition to the community and the licence period}

The impacts of these barriers continued into the community. The primary institutional barrier for CRC practitioners concerned large caseload numbers. This meant that officers were not encouraged, or able, to undertake prison visits and establish working relationships prerelease. Service users were often not allocated pre-release, meaning the initial appointment was often very brief and uninformative. Once allocated, officers employed a model of allocating service users to pathway services, such as housing, or employment advisors, encouraging an 'arm's-length' distant approach. However, due to austerity measures, many services were often poor and unable to help service users overcome problems related to housing or accessing benefits. Temporal barriers also persisted, as the limited time individuals had to serve on licence often meant that supervision was very perfunctory and something to 'get service users through' and onto PSS as painlessly as possible.

Under these challenging circumstances, practitioners had a more pragmatic attitude towards recalling individuals back to custody, seeing it as an inevitable part of the job for such a 'problematic' cohort. Often service users were bifurcated between those deemed willing and able to change, and those that were not. 
However, research on the through-the-gate elements of the reforms (CJJl, 2016; Taylor et al., 2017) and PSS (HMIP, 2019; Cracknell, 2020) are highly critical of the support provided to individuals on short sentences. My argument here is that there is a disconnect between TR policy rhetoric and the reality of practice on the ground which is caused by a set of interconnected institutional, temporal and political-economic barriers that practitioners struggle to overcome. I conclude by briefly looking at the incoming resettlement policy - offender manager in custody (OMiC) - evaluating the extent to which this latest resettlement policy will be able to address any of the current concerns related to resettlement for the short sentence population.

\section{Post-sentence supervision}

Staff administrating the last element of the short sentence - PSS - also experienced a number of barriers to providing effective support. There were ambiguities over the transfer process and eligibility criteria for PSS, and many practitioners experienced poor communication with third-sector staff, leading to an antagonistic relationship on the ground.

Furthermore, the expressed aim of rehabilitation was undermined by the same insufficient austerity-hit pathways that CRC practitioners faced. Third-sector staff felt that they were placed in a very difficult position, as the cases they took on had received little pre-existing resettlement support, yet were charged with starting again with the service user.

This meant there was a lack of continuity and efficient communication at all levels of the short sentence, encompassing prison, through to the community. Service users experienced the short sentence as three disparate elements; where resettlement work became stalled at every juncture of the sentence and then needlessly repeated. This was experienced as a negative pass-the-parcel process, with the individual repeatedly moved onto different practitioners and agencies throughout the sentence.

\section{Conclusion: resettlement policy post-TR}

As the failed TR model has now come to an end and probation services are re-unified, this provides an opportunity for an improved resettlement service. The main new initiative involves the OMiC model, which combines offender management work with resettlement planning - hoping to end duplication between these two functions (HMPPS, 2020). Most significantly, it places more emphasis on prisons, making them responsible for resettlement work, only handing over responsibility shortly before release. However, with prisons still struggling with the impacts of austerity, it is questionable if they are best placed to facilitate resettlement. 
In the community, specialised short sentence teams will be arranged in each probation area, these dedicated teams will aim to reduce the disruption caused by short periods of incarceration. This is potentially a welcome step towards addressing the difficulties this group often face. Despite some calls for its abolition, PSS will continue.

However, this element of the sentence will now be fully supervised by probation practitioners rather than third-sector organisations, hopefully aiding continuity in the supervisory relationship. Furthermore, greater flexibility has been bought into the supervision arrangements for individuals when they reach this stage of the short sentence such as removing the monthly minimum contact requirement.

Many of these changes cautiously indicate some progress in the resettlement support for individuals subject to short sentences. However, to improve resettlement outcomes for individuals, it is imperative that the government increases financial support in the important areas directly related to resettlement, such as benefits, housing and mental health support, to help individuals integrate back into society. Furthermore, prison and probation staff need to be provided the space and time to work effectively with individuals and build a trusting professional relationship. Without these changes, I fear that OMiC will fare little better than the failed TR reforms.

\section{Bibliography}

Cracknell, M. (2020). Post-sentence supervision: A case study of the extension of community resettlement support for short sentence prisoners. Probation Journal, 67(4), pp.340-357. https://doi. org/10.1177/0264550520942834

Criminal Justice Joint Inspection (CJJ). (2016). An inspection of through the gate resettlement services for short sentence prisoners, London: HM Inspectorates of Probation and HM Inspectorates of Prisons.

HM Inspectorate of Probation (HMIP). (2019). Postrelease supervision for short-term prisoners: The work undertaken by Community Rehabilitation Companies, Manchester: HMI Probation.

HM Prisons and Probation Service (HMPPS). (2020). A Draft Target Operating Model for the Future of Probation Services in England and Wales Probation Reform Programme. London: HMPPS.

Ministry of Justice. (2013). 70 resettlement prisons announced for England and Wales. London: Ministry of Justice. [Accessed on, 05/01/21]. Available at: https://www.gov.uk/government/news/70resettlement-prisons-announced-for-england-andwales

Taylor, S. Burke, L. Millings, M. and Ragonese, E. (2017). Transforming Rehabilitation during a penal crisis: A case study of Through the Gate services in a resettlement prison in England and Wales, European Journal of Probation, 9(2), pp.115-131. https://doi. org/10.1177/2066220317706438 